\title{
Tsunami risk assessment in Indonesia
}

\author{
G. Strunz ${ }^{1}$, J. Post ${ }^{1}$, K. Zosseder ${ }^{1}$, S. Wegscheider ${ }^{1}$, M. Mück ${ }^{1}$, T. Riedlinger ${ }^{1}$, H. Mehl ${ }^{1}$, S. Dech ${ }^{1}$, J. Birkmann ${ }^{2}$,

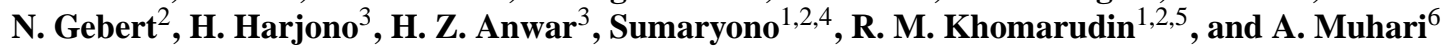 \\ ${ }^{1}$ German Remote Sensing Data Center, German Aerospace Center (DLR), Oberpfaffenhofen, Germany \\ ${ }^{2}$ United Nations University, Institute for Environment and Human Security (UNU-EHS), Bonn, Germany \\ ${ }^{3}$ Indonesian Institute of Sciences (LIPI), Research Center for Geotechnology, Bandung, Indonesia \\ ${ }^{4}$ National Coordinating Agency for Surveys and Mapping (BAKOSURTANAL), Cibinong, Indonesia \\ ${ }^{5}$ National Institute of Aeronautics and Space (LAPAN), Jakarta, Indonesia \\ ${ }^{6}$ Ministry of Marine Affairs and Fisheries (DKP), Jakarta, Indonesia
}

Received: 30 June 2010 - Revised: 31 October 2010 - Accepted: 1 November 2010 - Published: 5 January 2011

\begin{abstract}
In the framework of the German Indonesian Tsunami Early Warning System (GITEWS) the assessment of tsunami risk is an essential part of the overall activities. The scientific and technical approach for the tsunami risk assessment has been developed and the results are implemented in the national Indonesian Tsunami Warning Centre and are provided to the national and regional disaster management and spatial planning institutions in Indonesia.

The paper explains the underlying concepts and applied methods and shows some of the results achieved in the GITEWS project (Rudloff et al., 2009). The tsunami risk assessment has been performed at an overview scale at sub-national level covering the coastal areas of southern Sumatra, Java and Bali and also on a detailed scale in three pilot areas. The results are provided as thematic maps and GIS information layers for the national and regional planning institutions. From the analyses key parameters of tsunami risk are derived, which are integrated and stored in the decision support system of the national Indonesian Early Warning Centre. Moreover, technical descriptions and guidelines were elaborated to explain the developed approach, to allow future updates of the results and the further development of the methodologies, and to enable the local authorities to conduct tsunami risk assessment by using their own resources.
\end{abstract}

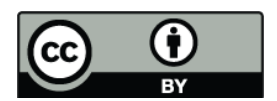

Correspondence to: G. Strunz (guenter.strunz@dlr.de)

\section{Introduction}

In response to the disastrous tsunami event on 26 December 2004 and to support the implementation of a reliable tsunami early warning system (TEWS) in the Indian Ocean, Germany offered its technical support for the development and installation of a TEWS at the UN World Conference on Disaster Reduction in Kobe in January 2005. Based on a joint declaration between Indonesia and Germany, the development and implementation of a TEWS in the framework of the GITEWS project was initiated (Rudloff et al., 2009).

Effective early warning systems have to integrate four elements (Basher et al., 2006; UN/ISDR, 2006):

1. The knowledge of the risks.

2. The technical monitoring and warning service.

3. The dissemination and communication of meaningful warnings to those at risk.

4. The public awareness and preparedness to react to warnings.

Therefore, the assessment and the knowledge of risk is an essential component of a people-centred early warning system and contribute significantly to disaster risk reduction (Basher et al., 2006; UN/ISDR, 2006). The knowledge about the geographical areas, which are prone to natural hazards, the exposed elements, their susceptibility, coping and adaptation mechanisms is a precondition for the development of people-centred warning structures, evacuation planning, emergency relief and recovery policy planning (e.g. Turner et al., 2003; Birkmann, 2006; Wisner et al., 2004).

Published by Copernicus Publications on behalf of the European Geosciences Union. 
Traditionally risk assessment urges at determining the likelihood of specific losses and damages, which includes population, economy, supporting environment and institutional structures (UNESCO-IOC, 2009a, b). Various attempts have been made to measure risk and vulnerability in the last couple of years at various scales (UNDP, 2004; Dilley et al., 2005; Cardona, 2006; Schneiderbauer, 2007; Cutter and Flinch, 2008). Global and regional approaches such as UNDP's Disaster Risk Index (DRI) (UNDP, 2004) and the Hotspots project by Columbia University (Dilley et al., 2005) measure relative levels of vulnerability at national level by using historical annual mortality rates, economic loss rates and exposed populations to different hazards (Birkmann, 2006). A paradigm shift in risk assessment can be recognized from pure quantification of probability of losses and damages of elements at risk due to a hazard (purely related to exposure and susceptibility considerations of elements at risk) towards the explicit consideration of coping and adaptive capacities and deficiencies in preparedness of society. Risk in the context of early warning and response is here defined as the conditions that increase the likelihood of the population being exposed to tsunamis and the assessment to which degree the population is able to have access to tsunami warnings and adequately respond to warnings, to find a safe place in due time and hence to become casualties by the tsunami. Strong focus is laid on the necessity to provide dedicated information for risk management in the fields of early warning chain planning, evacuation and emergency relief and rising preparedness and awareness.

This article describes the basic principles and methods as well as some of the main results of the tsunami risk assessment in the framework of the GITEWS project. In Sect. 2 an overview on the conceptual framework is given. Section 3 explains the methodological approaches for the hazard, vulnerability and risk assessment. In Sect. 4 the results are presented for the sub-national level analyses covering the coastal areas of southern Sumatra, Java and Bali and as well as for the detailed analyses in three pilot areas. Key parameters from this analysis are integrated in the decision support system of the Indonesian Early Warning Centre. Finally, in Sect. 5, the main results are summarized and conclusions are drawn.

\section{Conceptual framework and objectives}

From the beginning of the GITEWS project, the concept and the methods for risk assessment as well as the final products were developed in a joint Indonesian-German Working Group on Risk Modelling and Vulnerability Assessment. The activities were focussed on two main objectives:

- To provide risk information on a coarse overview map scale for large coastal areas, which serves as a first "broad-scale" risk assessment and from which a set of

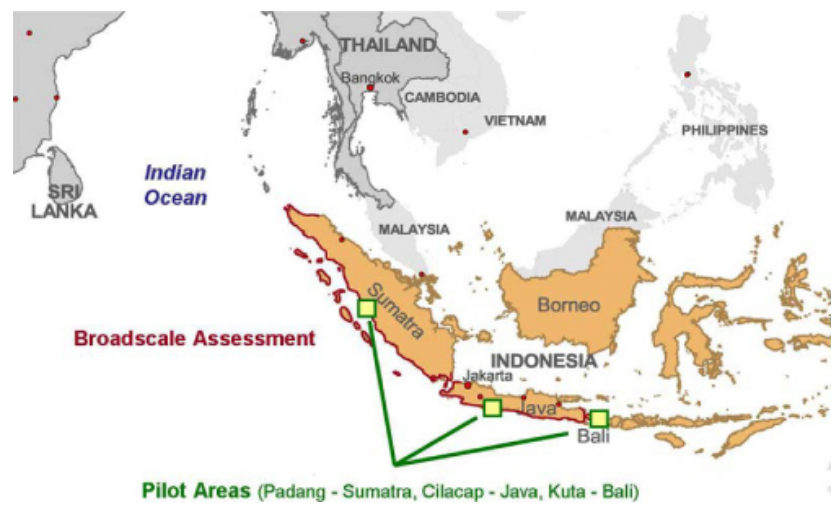

Fig. 1. Areas of tsunami risk assessment: broad-scale analysis for the coastal regions (depicted in red) and detailed analysis in the three pilot areas Padang, Cilacap and Kuta (depicted in green).

key parameters can be derived that is relevant for the early warning system and the warning process.

- To provide risk information based on a "detailed-scale" assessment for selected pilot regions, which serves as basis for the disaster preparedness and for the development of disaster risk reduction and mitigation strategies conducted by the local authorities.

The first objective addresses the provision of tsunami risk information at a sub-national scale and its use in tsunami early warning and response. The second objective addresses the provision of tsunami risk information at a local scale to support community preparedness and awareness strategies, early warning chain and evacuation planning as well as emergency relief and recovery efforts. This more indepth risk analysis has been developed and applied in three pilot areas with the aim to provide methodologies that are transferable to other regions.

Figure 1 shows the regions for the "broad-scale" assessment. These are the west coast of Sumatra, the south coast of Java and the south coast of Bali. The mapping scale for this assessment corresponds to 1:100000. The detailed assessment is performed in three pilot areas. These are Padang (Sumatra), Cilacap (Java) and Kuta (Bali). The scale of the detailed analysis corresponds to 1:25000 and even better.

In general, the risk assessment integrates the analyses of hazard, vulnerability and preparedness. The hazard assessment provides information about the geographical extent of inundation and the probabilities that these areas are likely to be affected. The vulnerability analysis provides information about the losses and damages with respect to social, physical, economic or environmental aspects or with respect to different sectors of development. The preparedness assessment characterizes possible limitations which inhibit the community to respond adequately and efficiently. 


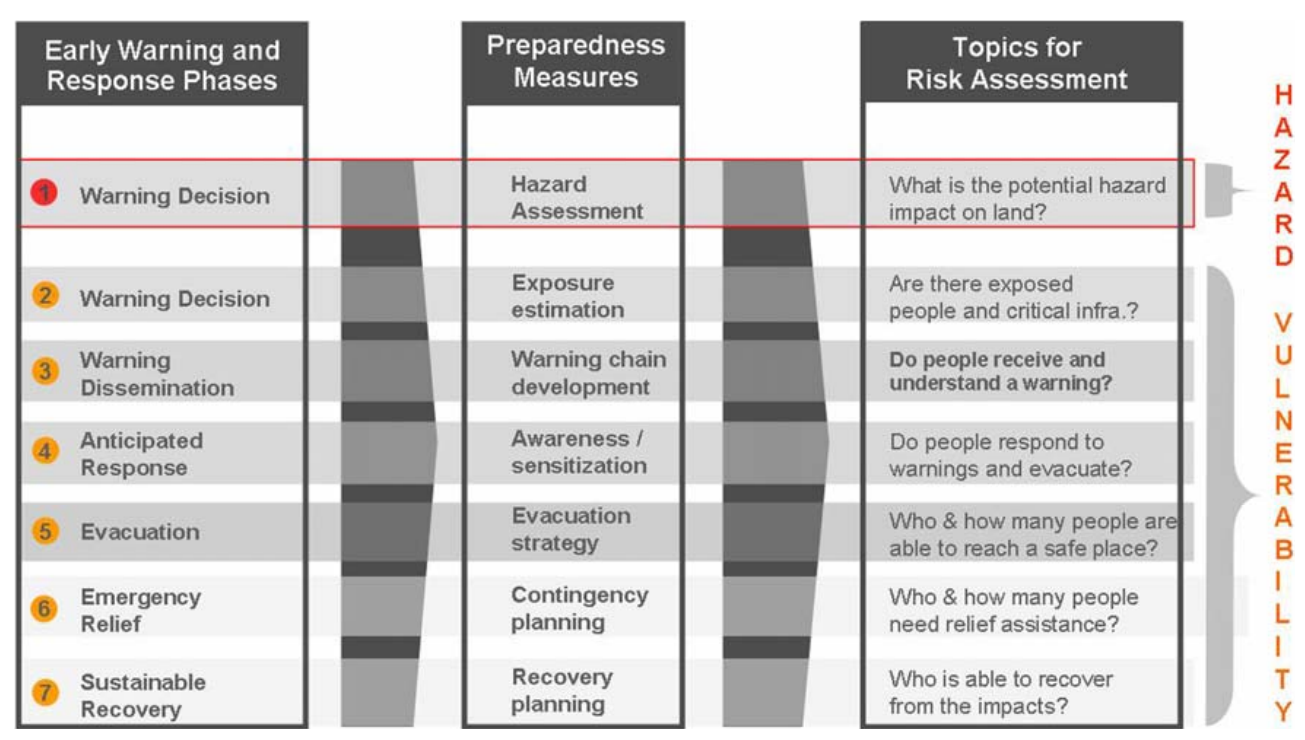

Fig. 2. Tsunami risk assessment framework for people-centred early warning.

The conceptual approach used for the tsunami risk assessment in the GITEWS project is based on the BBCframework (Birkmann, 2006). This approach involves the quantitative or qualitative description of indicators and it encompasses social, physical, economic and environmental aspects. This general approach has been adopted and modified in order to be applied for the tsunami risk assessment focussing particularly on people exposed to tsunami in terms of loss of life.

The underlying risk assessment approach is shown in Fig. 2. The hazard and vulnerability assessment covers components, which are relevant for the early warning and response phase as well as for the disaster preparedness and mitigation.

\section{Tsunami risk assessment}

This chapter describes the consecutive steps for the tsunami risk assessment and the underlying methods.

\subsection{Assessing tsunami hazard}

\subsubsection{Hazard assessment methods}

Tsunami hazard assessment is aiming at assessing the geographical extent of the tsunami affected area, the intensity of the tsunami impact and the probability of the occurrence. This encompasses the following main steps:

- Identification of the possible tsunami sources.

- Modelling of the tsunami propagation and its inundation on land.
- Determination of physical parameters of the inundation (e.g. inundation maximum, run-up height).

- Analysis of the probabilities or return periods of the tsunami events.

- Presentation of the results through hazard maps.

The output and the quality of the tsunami hazard analysis are very much dependent on the available data and the used methodological approach. In general, the approaches range from simple empirical methods to sophisticated numerical simulations.

Empirical methods use simplified formulas to derive tsunami hazard maps. In general, information on the terrain heights and the distances to coast are used in combination with empirical formulas to estimate the inundated areas on land. This method classifies the coastal areas hazard classes and, as far as possible, assigns empirically derived probabilities to these classes. These probabilities can be derived by statistical analysis of historical data and available tsunami databases. Further developments of this approach also take into account geo-morphological structures and surface roughness based on the land use (e.g. Federici and Cosso, 2006). The advantage of these approaches is that they can be easily applied with moderate requirements with respect to the necessary data and modelling capabilities. The disadvantage of empirical models is that they are not able to reflect local characteristics adequately and that the degree of uncertainty in the results obtained is consequently higher than using numerical methods representing the hydraulic processes (e.g. roughness effects).

Numerical methods calculate the tsunami propagation and inundation on land based on physical models. The numerical methods have the advantage that the results of tsunami 
models provide also hydraulic parameters, which can be used for a more detailed analysis of the tsunami hazard. Most commonly in these approaches, a set of realistic scenarios is simulated and the impacts on land are analysed for each of the scenarios. In some approaches, the worst-case scenario or the "most credible" scenario is selected from this set of scenarios and the hazard assessment is then based on the detailed analysis of this single scenario (Borrero et al., 2006; Sieh et al., 2009).

In the GITEWS project a method has been developed and applied, which is based on a "multi-scenario approach". This concept is described in the following sub-chapter.

\subsubsection{Multi-scenario approach}

The multi-scenario approach consists of the following steps: (1) the identification of the possible tsunami sources and the approximate assignment of probabilities to these events; (2) the modelling of the tsunami propagation and its inundation on land; (3) the multi-scenario aggregation and computation of statistical parameters for the potentially inundated areas, which is based on the analysis of all scenarios; (4) the derivation of the probabilities for inundation based on the uncertainty propagation using all scenarios; and (5) the generation of the hazard maps.

\section{Step 1}

For the identification of possible tsunamigenic sources, in general, earthquake sources and non-earthquake sources, like volcanic eruptions or submarine landslides, have to be taken into consideration. In our case the scenarios are based solely on earthquake sources, which are the most frequent sources for tsunamis in the Sunda arc. The locations, magnitudes and rupture parameters for the tsunamigenic sources along the Sunda trench are calculated for a large number of possible events. Details are given in Babeyko et al. (2010). Figure 3 shows the locations of the modelled earthquake scenarios. For each of these locations source parameters for the different earthquake magnitudes are calculated.

The assignment of probabilities to these earthquake events is only possible in an approximate way and is based on the currently available knowledge and scientific investigations. This to the best of knowledge estimation is performed by a statistical analysis of historical earthquake and tsunami data bases as well as the analysis of available publications. The scientific analysis of Babeyko et al. (2010) was used as a basis to categorize the main zones of earthquake probabilities for the Sunda trench along the coasts of Sumatra, Java and Bali. For the assignment of probabilities to the different earthquake magnitudes, the data from the available tsunami catalogues were used as input to a regression analysis considering the Gutenberg-Richter Law (Gutenberg and Richter, 1954). Moreover, recent publications (McCloskey et al., 2008; Chlieh et al., 2008) were analysed and the

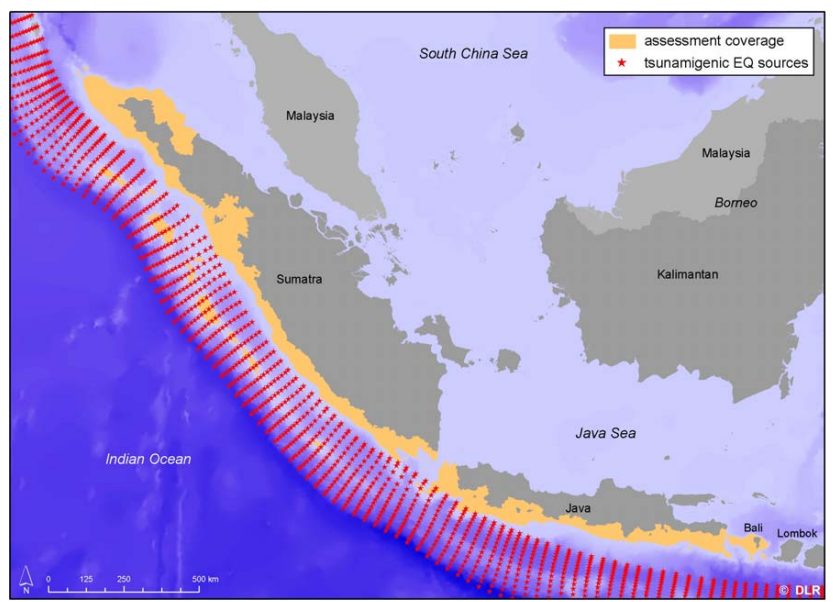

Fig. 3. The location of the tsunamigenic earthquake sources obtained from the scenario database used in the tsunami modelling. Each star represents characteristic elicitation parameters for different moment magnitudes (for details see Babeyko et al., 2010).

results were integrated in the analysis to further refine the assignment of reasonable probabilities to the earthquake scenarios.

\section{Step 2}

The tsunami modelling comprises three parts. At first, the earthquake parameters (tsunami source parameters) are used to calculate the size and the shape of the initial tsunami wave. Secondly, the tsunami propagation across the ocean is modelled. The final component is the calculation of the inundation of the tsunami wave on land. In the GITEWS project the tsunami modelling is performed by the Alfred Wegener Institute. About 2000 scenarios along the Sunda trench with earthquake moment magnitudes ranging from 7.5 to 9.0 are currently being calculated using the TsunAWI model (Behrens et al., 2010). Moreover, for the pilot areas a more detailed tsunami modelling with higher spatial resolution is performed by the GKSS Research Centre (Gayer et al., 2010).

\section{Step 3}

The multi-scenario aggregation is performed for all scenarios and for the whole coastal areas as shown in Fig. 1. Based on the results of the previous step, for each modelled scenario the spatial extent of the inundated area, the wave heights at coast and the estimated times of arrival (ETAs) of tsunami waves are analysed. The multi-scenario aggregation statistically combines the results from each of the scenarios. The basic approach to derive the inundation probability along the coast using the multi-scenario approach is to geographically overlay the inundation results from all scenarios and to determine how often a point on land is significantly inundated (assuming e.g. a flow depth higher than $0.5 \mathrm{~m})$. 
Moreover, as additional information, the determination of the hazard areas is linked to the tsunami warning levels, which are used in the Decision Support System (DSS) as defined in the national Indonesian Tsunami Early Warning Centre (Raape et al., 2008). The tsunami warning levels refer to different wave heights at the coast, where (a) wave heights between $0.5 \mathrm{~m}$ and $3 \mathrm{~m}$ at the coast lead to a "tsunami warning", and (b) wave heights higher than $3 \mathrm{~m}$ lead to a "major tsunami warning". Thus, the derived tsunami hazard zones represent the impact for a specific warning level. These zones are derived by database queries and the subsequent categorization of the modelled tsunami scenarios according to their wave heights at the coast related to the respective warning levels. After the database query, the calculation of the number of tsunami impact hits on land in each of the two warning classes is performed. For this calculation the coastal area is represented by a point grid with a point density of about $50 \mathrm{~m}$. From this calculation using all scenarios the inundation areas with respect to the two warning levels are derived (see Fig. 4).

\section{Step 4}

In addition to the previous step, the probabilities for inundation based on the uncertainty propagation using all scenarios are derived. For this calculation the different likelihoods for the scenarios have to be taken into account. Therefore, the basic deterministic approach is expanded by including the different probabilities and integrating them in the analysis. This approach is comparable to a Probabilistic Tsunami Hazard Assessment (e.g. (Annaka et al., 2007; Burbidge et al., 2008; Geist et al., 2006; Gonzales, 2009; Power et al., 2007). Figure 5 shows the basic procedure of this approach. In principle, this method derives from the probability of occurrence for different earthquake magnitudes at different geographic locations, the probability of occurrence for a specific wave height at the coast and the probability for every point on land to get hit by a tsunami. These values are combined and quantified by a logical tree technique (Zosseder et al., 2009).

\section{Step 5}

The generation of the hazard maps is the last but not least important step. In order to communicate the results of the assessment, the visualisation in the form of maps is the most appropriate means. The layout and content of the maps has been elaborated in the above mentioned joint IndonesianGerman Working Group. In order to enable an efficient update of the maps, the map frame is designed according to the official topographic maps of Indonesia provided by the National Mapping Agency BAKOSURTANAL. This allows for a convenient update of the maps if e.g. the content of the topographic maps is updated. An example of a hazard map is given in Sect. 4 of this paper.

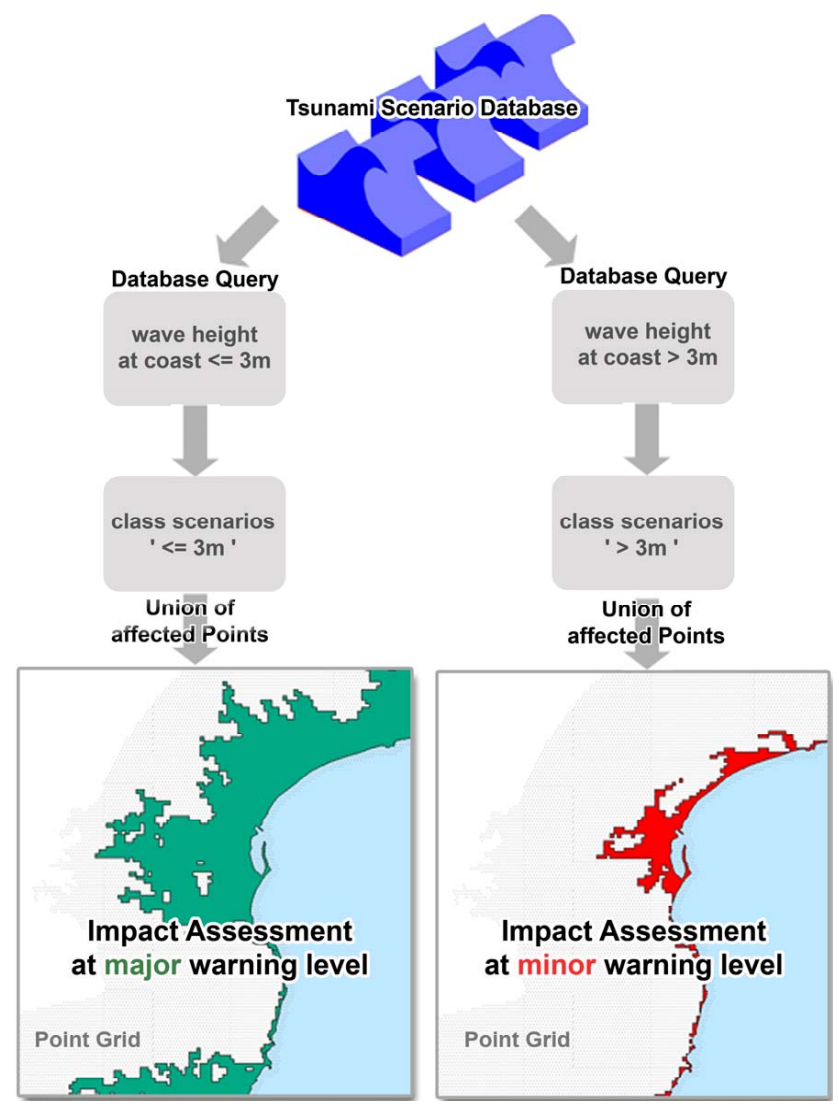

Fig. 4. Multi-scenario aggregation taking into account the different tsunami warning levels.

\subsection{Assessing vulnerability}

\subsubsection{Exposure estimation}

The analysis of the vulnerability requires reliable information about the population and the critical assets that are exposed to the tsunami hazard. In order to build up an adequate exposure database for the vulnerability analysis, it is necessary to have up-to-date information about these exposed elements. Among these, the knowledge of the distribution of people, the location and function of critical infrastructures and the location and types of buildings, are of high importance.

Information about the distribution of people is mainly based on data sources provided by official statistical catalogues. However, the problem is that these data are in most cases only available for administrative units. This means that per each administrative unit e.g. one value is provided and no spatially explicit population distribution map. Therefore, a method has been further developed and applied to provide information on population distribution based on a combination of statistical data and remote sensing information. 


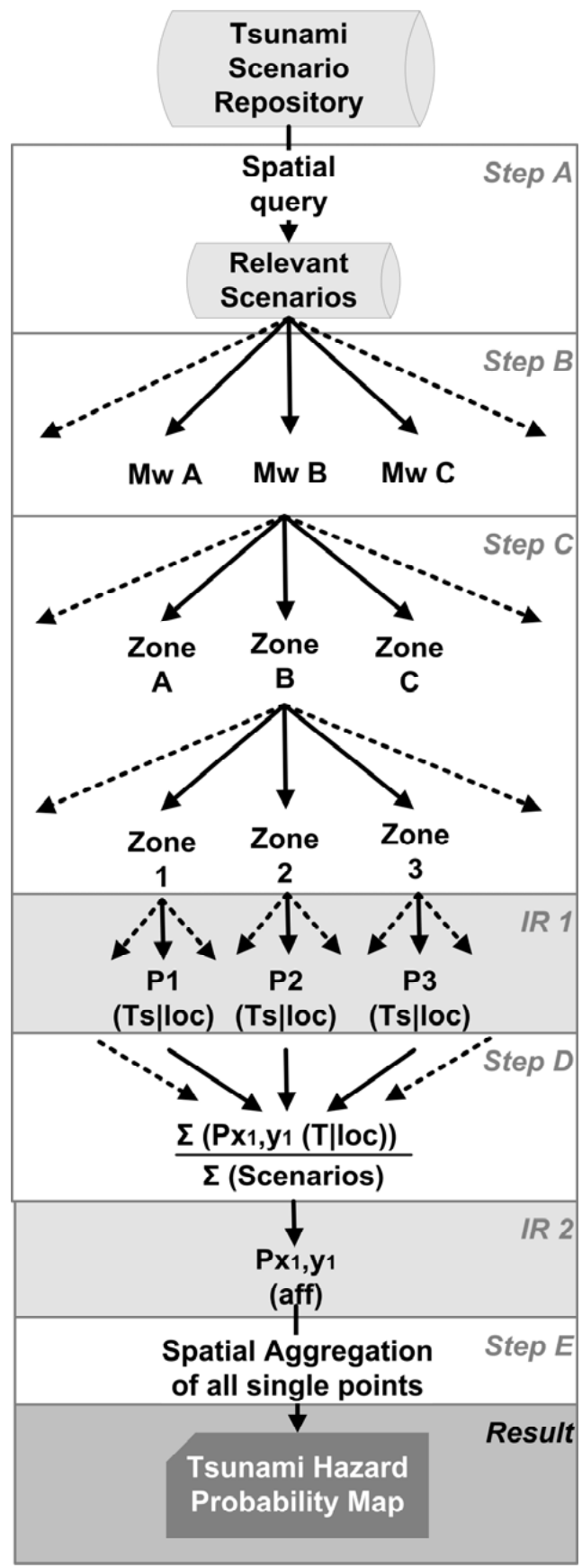

Fig. 5. Principle scheme for the aggregation of various scenarios and their probabilities in the multi-scenario approach.

The basic principle of this population distribution modelling is that the statistical data are disaggregated on the basis of land use data, which are derived from remote sensing based land use mapping or from topographic maps. For each administrative unit, the number of people is assigned to the sub-units provided by the different land use classes. This results in a spatially explicit representation of population distribution maps. Moreover, by integrating additional information, also day-time and nighttime population distribution can be modelled. The approach is described in detail in Khomarudin et al. (2010).

Information about the distribution and categorization of buildings is of importance both for the hazard as well as for the vulnerability assessment. For the hazard assessment the information about the location of buildings is an important input for the modelling of the inundation on land, especially for the very detailed scales. For the vulnerability assessment the mapping of buildings is important in order to categorize the buildings into different vulnerability classes. Moreover, of specific relevance for the tsunami risk assessment is the identification of those buildings that are suitable as shelter buildings for vertical evacuation.

The approach, which has been developed in GITEWS, is based on a combined approach using in-situ assessment and remote sensing. In a first step, a detailed assessment based on the selection of some representative buildings ("stratified sampling") is made. Geometrical and structural parameters of these buildings are acquired in an in-situ assessment. According to these parameters the sample buildings are categorized. These parameters are then used to develop the classification rules for the extraction and categorization of all buildings from high resolution satellite data. The approach is based on a decision tree algorithm and on object based image interpretation. In Fig. 6 the workflow of the building extraction and categorization is shown. The method is described in more detail in Sumaryono et al. (2008).

\subsubsection{Assessing response capabilities and preparedness}

The analysis of the response capabilities and community preparedness to tsunami warnings is an important issue in vulnerability assessment. With reference to Fig. 2 this assessment has to answer the following questions:

- Warning dissemination: Do people receive and understand the warning?

- Anticipated response: Do people respond to warnings and evacuate?

- Evacuation: Are people able to reach safe areas on time?

The quantification of human response capabilities is a complex issue that involves the consideration of all aspects that influence the people's ability to reach a safe area after receiving the tsunami warning.

Figure 7 illustrates the time sequences from the moment of the tsunami detection until the evacuation of the population at risk. The time span, which is available for the evacuation, is defined by the estimated time of arrival (ETA) of the tsunami wave. The ETA is the time needed for the tsunami wave to propagate from the earthquake source location to the coast. Within this time frame, which is available from precomputed tsunami scenarios, the following steps have to be 


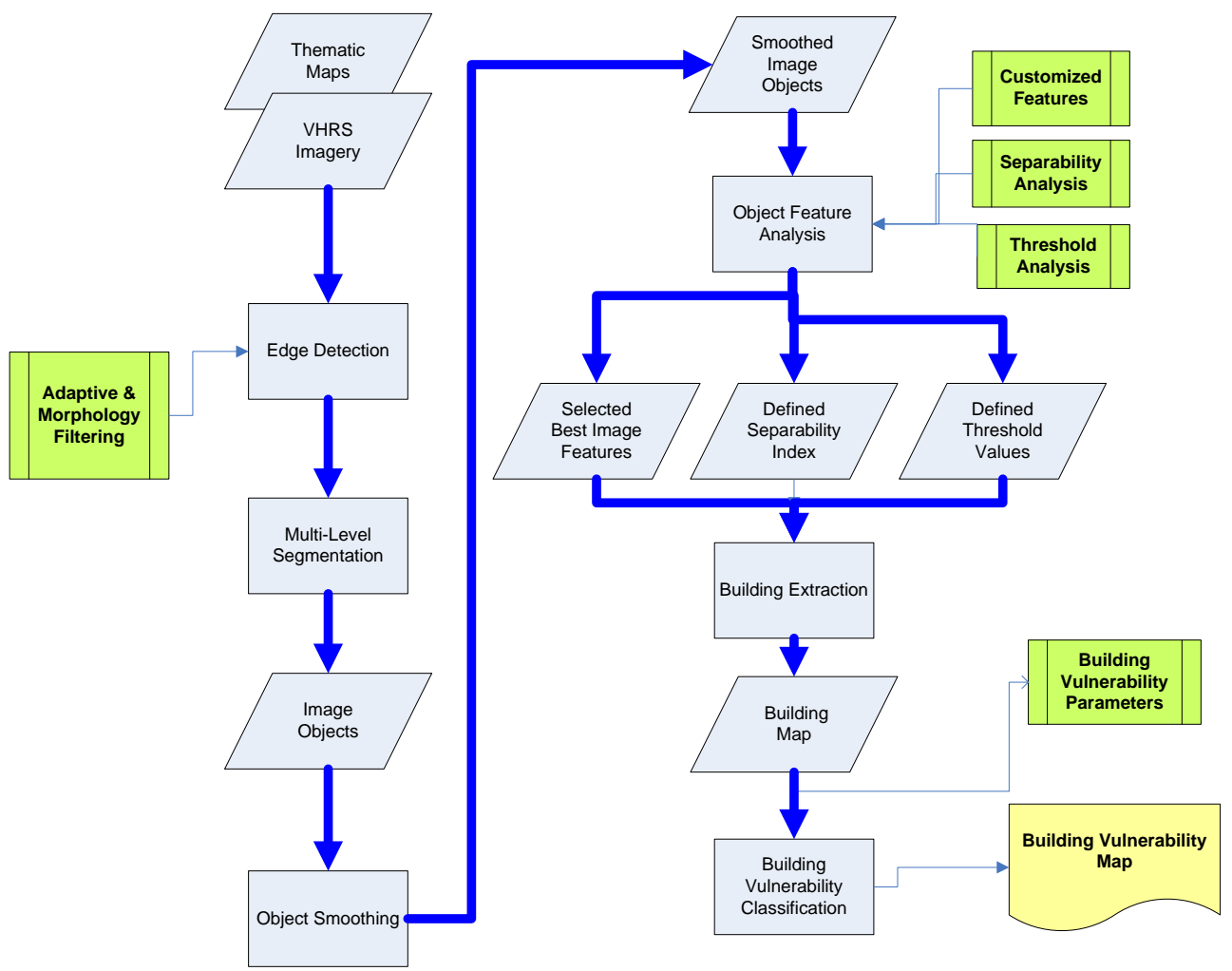

Fig. 6. Workflow of building extraction and categorization using high resolution remote.

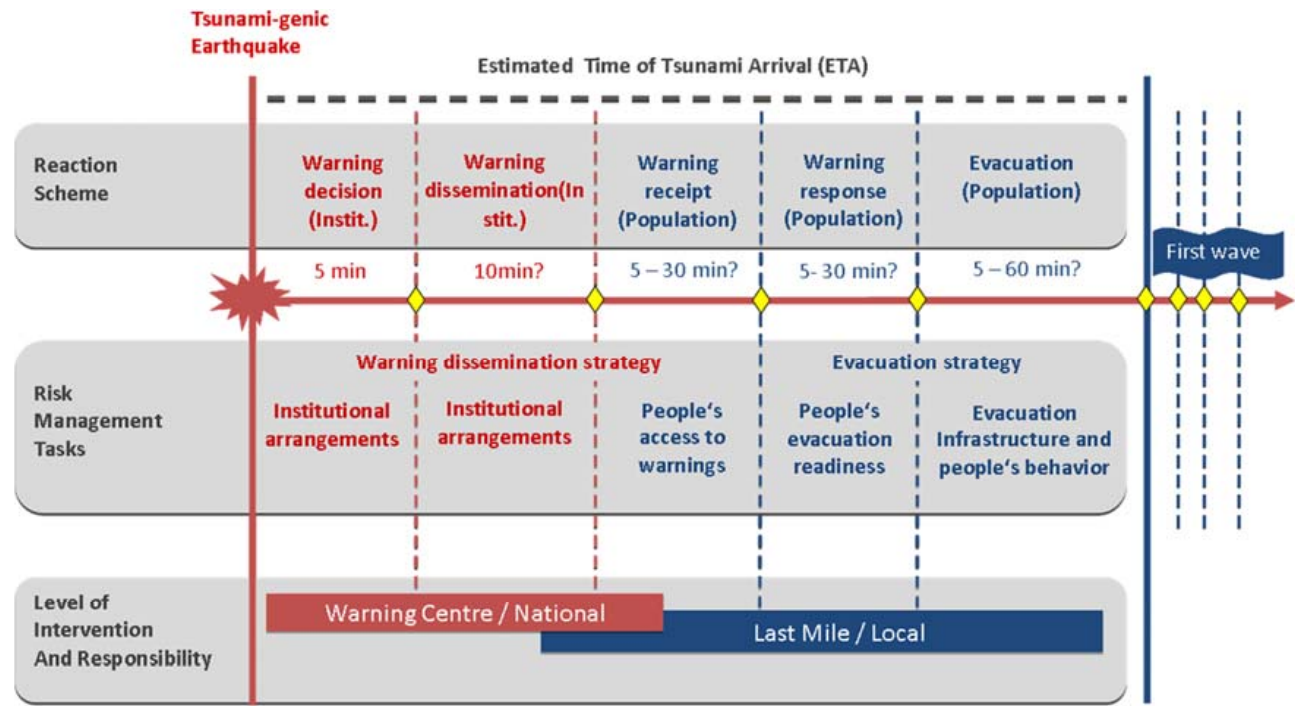

Fig. 7. Reaction scheme and time sequence for early warning and evacuation.

considered: (1) warning decision time (time consumed by detection of an event by sensor and monitoring systems until the warning decision), (2) warning dissemination time (time consumed through disseminating technically the warning to devices and institutions transmitting a warning signal to people at risk), (3) anticipated response time (time consumed from receiving of warning by people at risk until their decision to react and to evacuate) and (4) evacuation time (time people need for evacuation to reach a safe area). 
In quantifying the early warning time components (1)-(4) it is possible to assess human response capability towards a tsunami threat. If the sum of time of all four components is larger than ETA, then the response capability is weak and people do not have enough time to reach a safe place and are consequently most likely hit by the tsunami (Post et al., 2009).

The time components cannot be exactly quantified and can only be estimated. "Warning decision time" is determined by the effectiveness of sensor and monitoring systems and their data communication to the warning centre as well as the effectiveness of the decision mechanism in the warning centre to disseminate a warning. First experiences based on the GITEWS system and the SeisComP3 seismic system indicate that the warning decision based on earthquake information and pre-computed tsunami scenarios is possible within about 5 min (Hanka et al., 2010).

The "warning dissemination time" is determined by technical communication or transfer of a warning signal or message to warning devices distributed along the coast.

For the "anticipated response time" the human reaction upon receiving a warning message has to be analysed. In the GITEWS project the assessment of this time component at a sub-national scale is performed in a qualitative manner. Thereby indicator sets to resolve the guiding questions "Do exposed people have access to tsunami warnings and are warnings understood?" and "Do people respond to warnings and evacuate?" are derived and processed to a qualitative statement characterizing the human reaction in an early warning case.

For the estimation of the "Evacuation time" a GIS approach has been developed and applied. The basic principle of the assessment of evacuation time is to define the best evacuation route from a given point to a temporary shelter area or an evacuation building. Here the fastest path from that point to the shelter location has to be found. This fastest path from any endangered location to the nearest safe area is calculated on a cost surface which consists of a regular two-dimensional grid where each cell represents either passable routes such as roads, vegetation, sealed areas, agriculture or relatively inaccessible land and water bodies. The detailed methodology is described in (Post et al., 2009).

\subsection{Assessing tsunami risk}

Risk assessment combines the outputs of the hazard and the vulnerability assessments. In our people-centred approach the risk assessment is aiming at analysing the risk that people cannot reach safe areas on time and are hit by the tsunami. In the hazard assessment the hazard zones and the related hazard probabilities of being hit by a tsunami wave have been derived. In the vulnerability assessment the calculation of the response time has been related to the available time given by the ETA calculation. The time and event dependent calculation of casualties is described in Post et al. (2009).
For the broad-scale risk assessment a quantitative calculation according to the following equation has been adopted:

Risk (probability of loss of lives) = Hazard (probability of being hit by tsunami) - Vulnerability (probability of not reaching safe areas in time)

The probability of not reaching safe areas in time has been obtained by relating the time needed for evacuation to the median estimated time of arrival (ETA) and by normalizing the result to values between 0 and 1 . This is then multiplied by the tsunami hazard probability and classified to low, medium and high risk.

For the detailed assessment in the pilot areas the assignment of risk categories is performed on a quantitative as well as qualitative manner. Figure 8 shows a decision tree approach and applied thresholds to assign qualitative risk classes for the analysis in the pilot regions (Wegscheider et al., 2010). The assigned risk classes (very low, low, moderate, high and very high) are based on the probability of tsunami occurrence, the ability to evacuate on time to a vertical or horizontal shelter, and the population distribution.

The level of detail of this analysis is mainly depending on the scale and the quality of the available data. The broad-scale assessments are based on data available from topographic maps and national statistical data, whereas the assessments in the pilot areas are based on detailed data acquisitions from in-situ measurements and remote sensing data.

\section{Results and discussion}

\subsection{Tsunami risk assessment for coastal areas at an overview scale}

The broad scale assessment for the coastal areas resulted in maps of a scale 1:100000. These maps were generated and numbered in analogy to the official Indonesian topographic map sheets.

For each region the following maps were generated:

- Hazard map (hazard probability and hazard zones).

- Exposure map (population and critical facilities).

- Response map (evacuation time).

- Risk map (aggregated tsunami risk).

These maps provide an overview on the overall risk for the respective coastal region. Areas with high risk can be identified and can be used to prioritize mitigation measures. The high risk areas are characterized by a high probability of being hit by a tsunami and a low evacuation capability of the population. This means that people in high risk areas will be not able to reach a tsunami safe place in a time corresponding to the calculated median estimated time of tsunami arrival. 


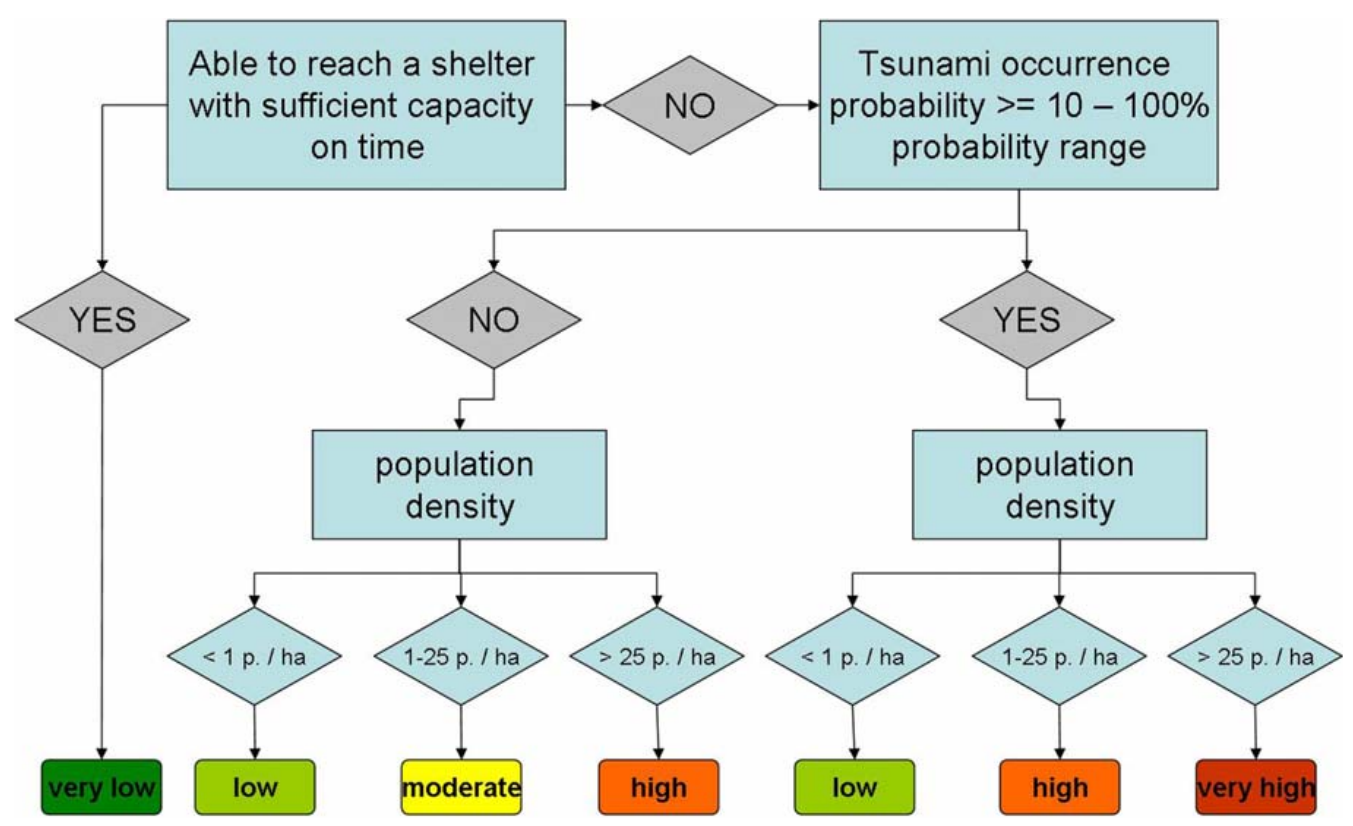

Fig. 8. Decision tree approach to assign tsunami risk classes.

Hence in these areas early warning chain and evacuation planning has to be prioritized first and options for e.g. vertical evacuation have to be elaborated. Also in high risk areas the highest probability of human losses can be expected allowing prioritising of emergency relief efforts. The planning of these measures, however, needs a more detailed analysis like the ones that have been performed in the pilot areas.

\subsection{Integration of tsunami risk parameters in the Decision Support System}

On the basis of these risk maps along the southern coasts of Sumatra, Java and Bali selected key parameters were derived and provided for the operational use in the early warning system. These values are pre-computed for the two cases of tsunami warnings and integrated into the Decision Support System (DSS) of the Early Warning System. These key parameters comprise the number of exposed people as well as critical facilities for each of the 118 warning segments along the coasts. This information is displayed for each of the affected warning segments in the DSS operational environment in the tsunami early warning centre (Steinmetz et al., 2010). Figure 9 shows the display of these parameters in the so-called decision perspective of the DSS. It provides the risk parameters for each of the affected warning segments in numerical tabular form and additionally as colour-coded values in the graphical map display.

\subsection{Detailed tsunami risk assessment in the pilot regions}

The detailed assessment in the three pilot regions provides the basis for the decision makers on community and regional level to improve the preparedness to tsunamis and to elaborate strategies to mitigate the tsunami risk. The results are provided in a map scale of 1:25000 and better. In the following the results for the pilot area Kuta (Bali) are shown. The same types of maps have been generated for Padang and Cilacap.

\subsubsection{Tsunami hazard map}

The tsunami hazard map shows the probability of tsunami occurrence (tsunami inundation with at least $0.5 \mathrm{~m}$ water depth) on land and the two hazard zones related to warning levels defined by the Indonesian Tsunami Warning System. It also provides the minimum and median values of the ETA. On the lower right side of the map the locations of the tsunamigenic sources are given, at which earthquakes along the Sunda Arc can cause impacts at the respective coastal area. As an improvement to the sub-national tsunami hazard map, the tsunami modelling results and scenarios are based on detailed inundation modelling using higher resolution bathymetric and topographic input data and numerical modelling including e.g. terrain roughness effects (Gayer et al., 2010). In Fig. 10 the tsunami hazard map for Kuta is shown.

\subsubsection{Population exposure map}

The degree of exposure of the population and location of critical facilities is shown in the map given in Fig. 11. Also the location of critical facilities is provided in the map. 


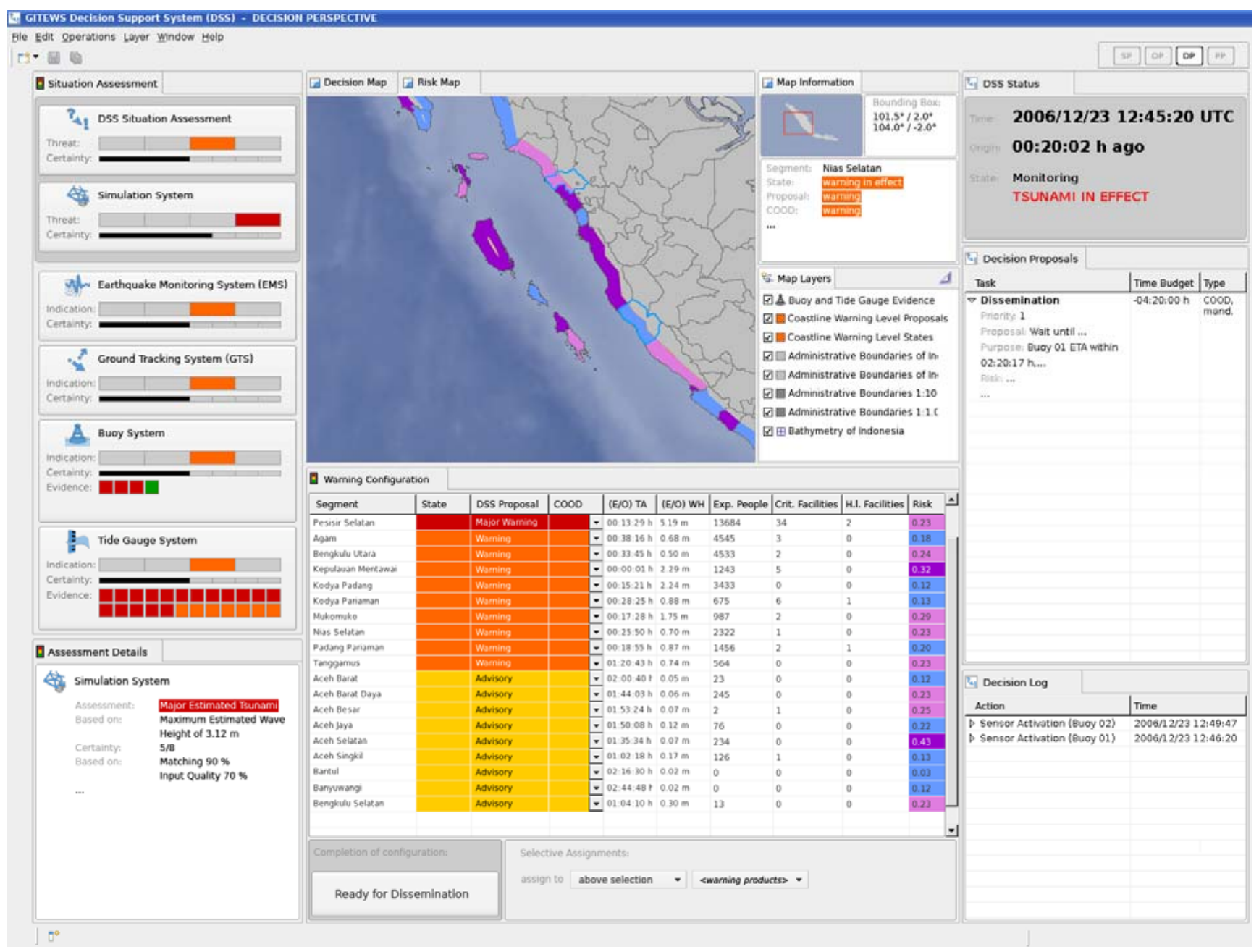

Fig. 9. Integration of tsunami risk parameters in the Decision Support System.

\subsubsection{Evacuation time map}

For the calculation of the evacuation time not only shelter areas, like open space and gathering areas outside the hazard zone, are taken into consideration. In addition to these "horizontal" evacuation areas also buildings, which are suitable for "vertical" evacuation, are included in the evacuation modelling. The evacuation times are calculated and categorized in different colours on the maps. Additionally the amount of people that is not able to evacuate in time is calculated and depicted on the map for each administrative unit (see Fig. 12).

\subsubsection{Tsunami risk map}

The tsunami risk map shows levels of risk from low to high based on the combination of the information given above. It highlights the areas with a strong need for additional evacuation capacities, i.e. mainly the planning of additional vertical evacuation buildings or shelters (see Fig. 13).

\subsection{Implementation and guidelines}

The resulting risk assessment products allow a thematic representation at a map scale of 1:100000 for the broadscale and 1:25000 for pilot areas due to the spatial resolution of input data (tsunami modelling results, socio-economic data and geospatial data). The broad scale assessment is based on available data sources which are regularly updated, e.g. the statistical data provided by the Statistical Bureau of Indonesia (BPS) and the tsunami simulation database of the Tsunami Early Warning System at the Indonesian Agency for Meteorology, Climatology and Geophysics (BMKG). Hence a regular update of risk information at this level is ensured. For the pilot areas novel data acquisition techniques have been developed. These encompass socio-economic household surveys to deduce vulnerability profiles, remote sensing techniques allowing better spatial representation of exposure and susceptibility of population and critical infrastructure, tsunami inundation modelling better reflecting 

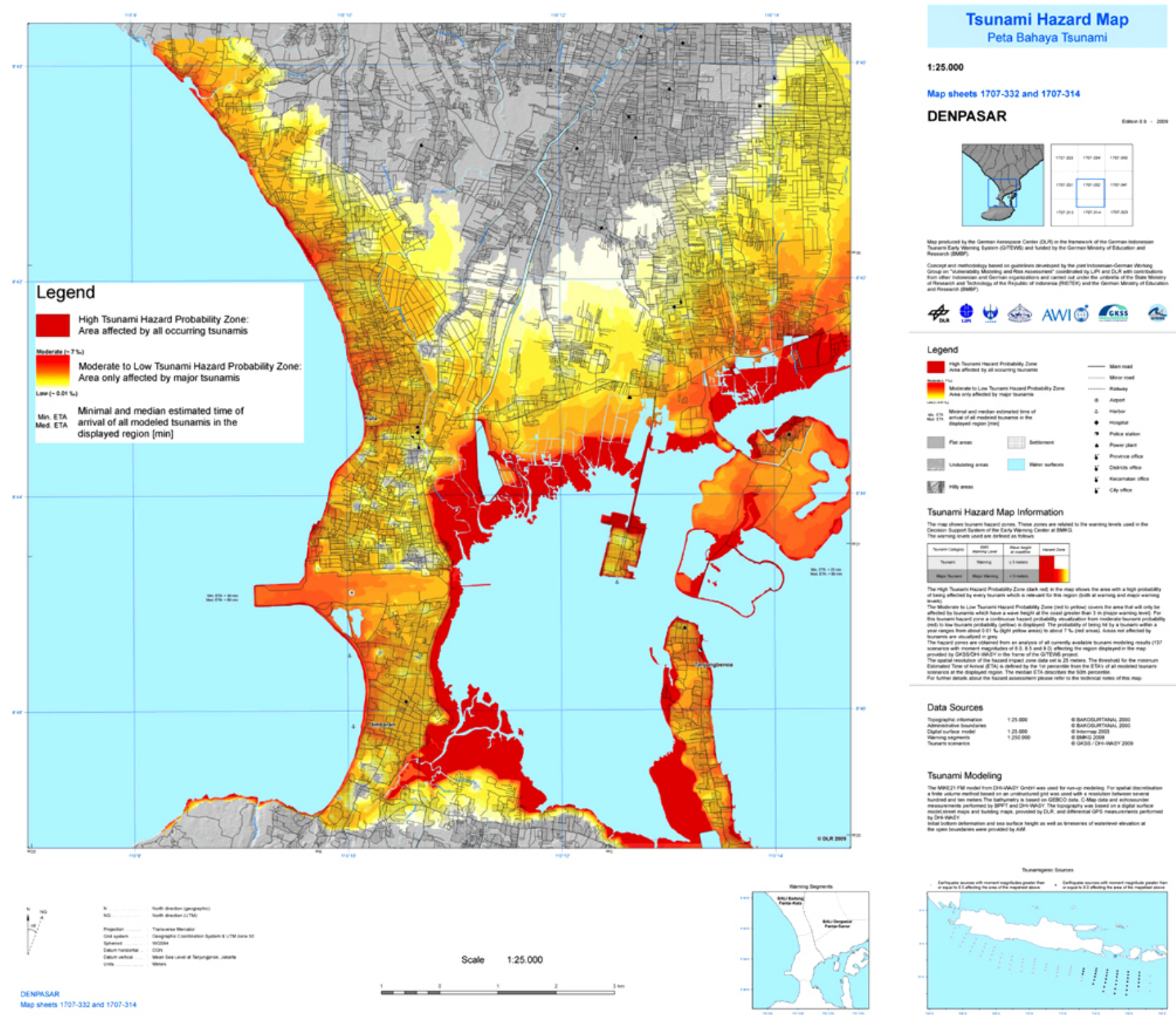

Fig. 10. Tsunami hazard map of Kuta (Bali).

surface roughness effects to address the needs of community level disaster risk management. This advanced risk assessment methodology and the thereof generated risk maps and information are seen as adequate to allow for an effective use for disaster risk reduction at this scale. Moreover, it provides a methodology that is transferable to other tsunamiprone regions.

Broad scale results contribute to information needs for disaster management from national down to local level. The results can be presented on different aggregation levels: on kabupaten (district) and kota (city) level, kecamatan (subdistrict) down to desa or keluharan (village) level and, last not least, for warning segments in the DSS. For the latter, selected risk information on key parameters and layers are provided for an operational use in the early warning case. This information shall provide risk related warning decision parameters (whether and when to warn), improvement of warning logic (e.g. where to warn in priority, improved spatial warning segmentation and level definition), and to provide post-disaster information (e.g. number of affected critical and high loss facilities and people, map of tsunami disaster impact area and severity). This information can be distributed in specific early warning and post-disaster products. For example, estimates on number of expected casualties together with spatial information on event specific tsunami impact areas are important 


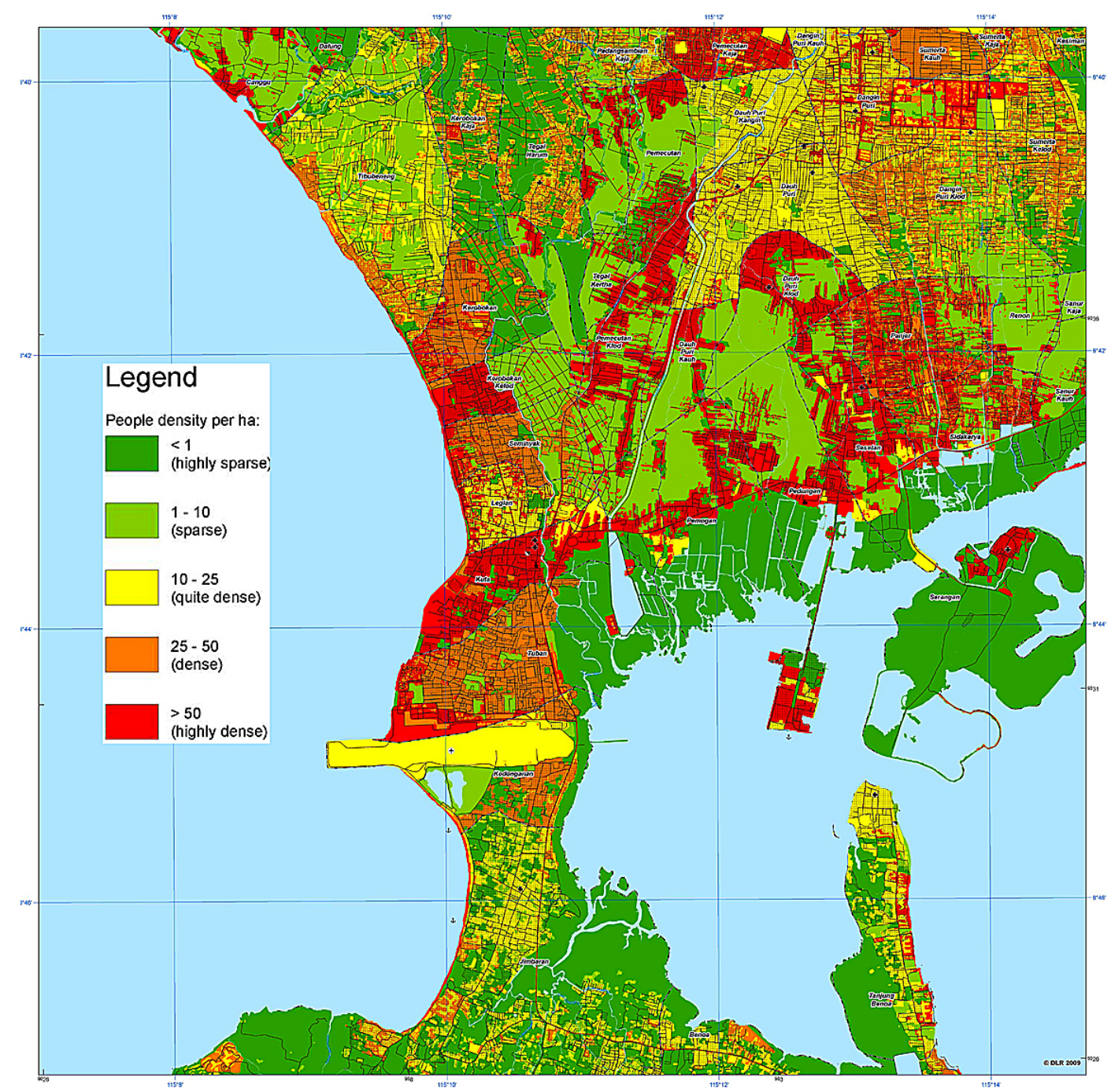

Fig. 11. Population exposure map of Kuta (Bali).

information to improve emergency relief efforts. On the other hand, tsunami risk assessment conducted in the pilot areas provides more detailed risk information which is linked to early warning information. The tsunami hazard map zones provided at local level reflect tsunami impact areas at the different warning levels issued in warning messages. Having this information beforehand allows evacuation planning according to information disseminated in warning products. In the future this might contribute to more effective evacuation procedures. Additionally the information on dynamic population distribution (day and night-time patterns) provided together with evacuation time maps and local level tsunami risk maps constitute useful information for evacuation shelter planning and assigning of evacuation routes and allow education and risk communication within the community and governmental authorities. People can learn about the approximate arrival times of potential tsunamis affecting their communities, what their potential evacuation time is, where tsunami safe areas are located and which routes to take during evacuation.

The provided knowledge about the tsunami risk and the mitigation of these risks are essential. Therefore, it is necessary to ensure that the products and maps are transferred to the relevant governmental disaster management and planning authorities. The essential step is the official acceptance and legislation of the results. This has to be based on the documentation of the technical and methodological aspects as well as on clear explanations and interpretations of the achieved tsunami risk results. It is important that the relevant stakeholders are integrated at an early stage. These processes need technical facilitation and the support of institutional structures and human resources in order to enable local authorities to use the provided risk information for their tasks. Within the GITEWS project and together with partners 


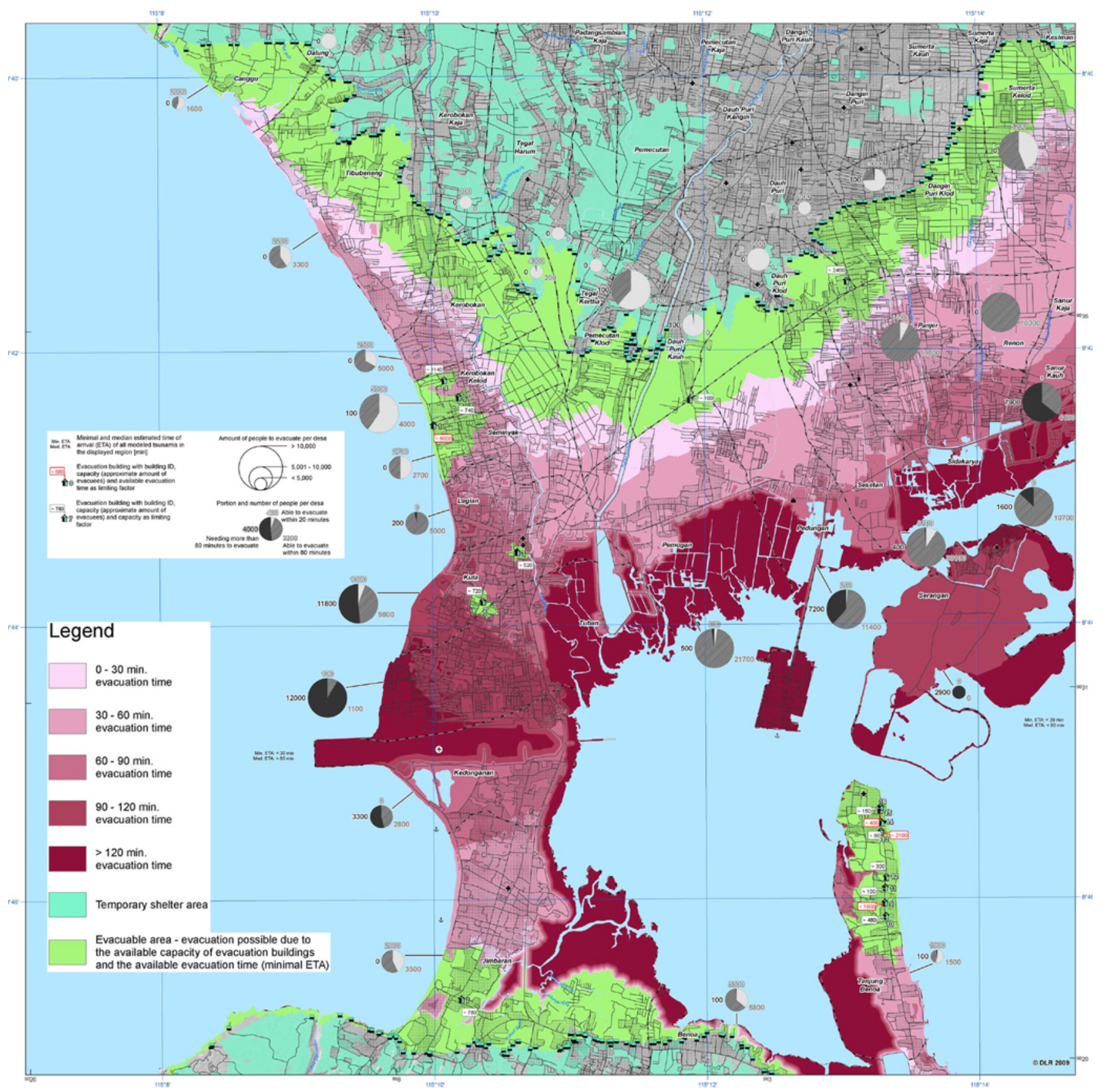

Fig. 12. Evacuation time map of Kuta (Bali).

of the joint Indonesian-German Working Group, first steps in this respect have been initiated in close cooperation with GTZ (GTZ-IS, 2009). Moreover, the GITEWS project has contributed to manuals and guidelines elaborated by the UNESCO Intergovernmental Oceanographic Commission (IOC) related to "Tsunami risk assessment and mitigation for the Indian Ocean" (UNESCO-IOC, 2009b) and on "Hazard awareness and risk mitigation in integrated coastal area management" (UNESCO-IOC, 2009a).

\section{Conclusions and outlook}

In the framework of the German Indonesian Tsunami Early Warning System the assessment of tsunami risk is an essential component. The concept and the methodological approaches have been elaborated in a joint IndonesianGerman Working Group in close interaction with disaster management authorities on the national and regional level in Indonesia. 


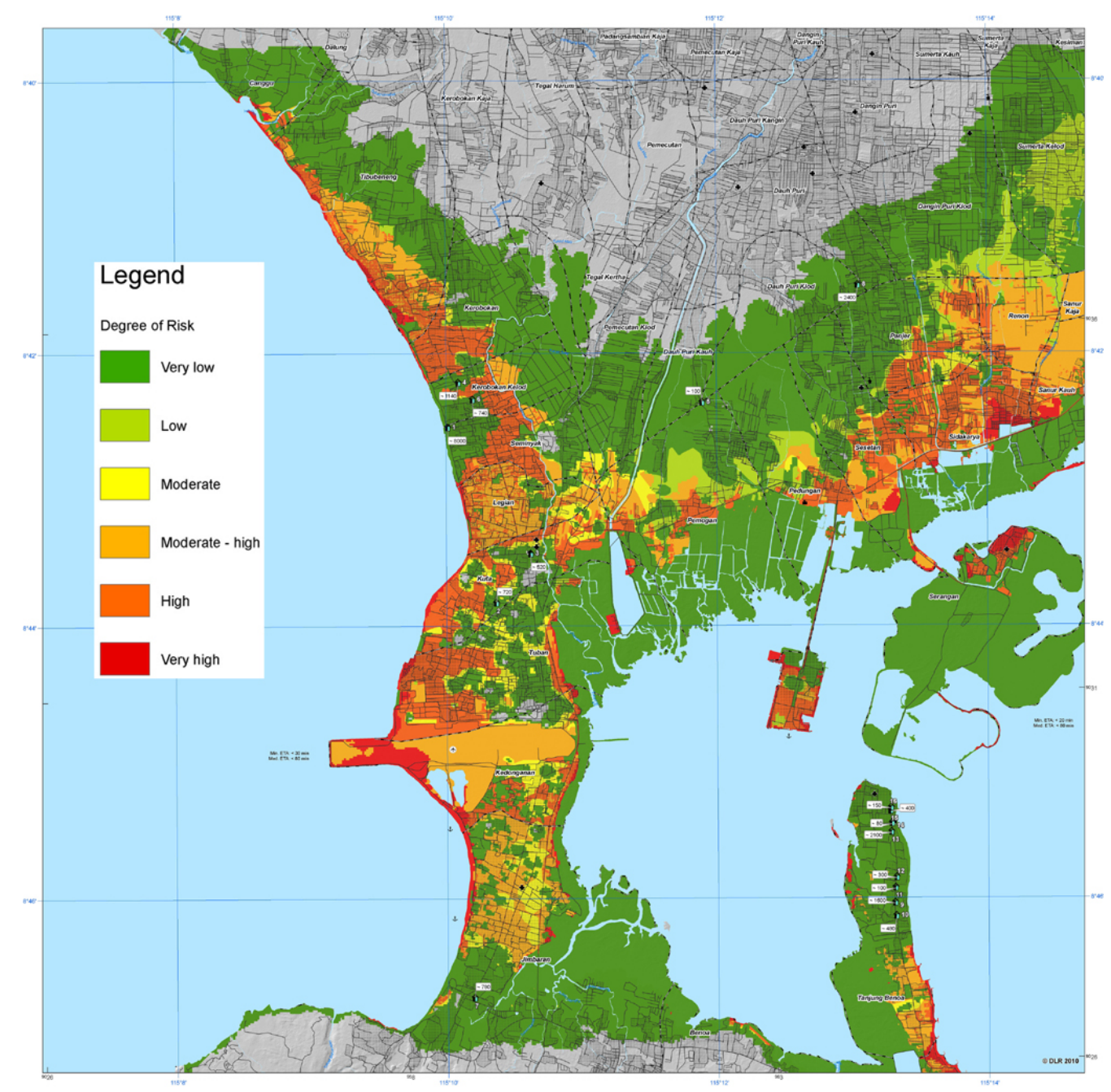

Fig. 13. Risk map of Kuta (Bali) highlighting the areas (in red) with high needs for tsunami evacuation buildings.

The assessment of the tsunami hazard is based on a multiscenario approach, which integrates pre-calculated tsunami modelling scenarios and takes into account the probabilities of the different scenarios. The vulnerability assessment focuses on the analysis of exposure, response and evacuation time.

The tsunami risk assessment has been performed at subnational level covering the coastal areas of southern Sumatra, Java and Bali and on a detailed level in the pilot areas Padang (Sumatra), Cilacap (Java) and Kuta (Bali). The results are provided as thematic maps and GIS information layers for the national and regional disaster management and planning institutions. From the analyses key parameters are derived, which are integrated and stored in the national Indonesian Early Warning Centre. Moreover, technical descriptions and guidelines were elaborated to explain the developed approach and to allow future updates of the results and the further development of the methodologies.
Acknowledgements. The GITEWS project (German Indonesian Tsunami Early Warning System) is carried out through a large group of scientists and engineers from (GFZ) German Research Centre for Geosciences and its partners from the German Aerospace Centre (DLR), the Alfred Wegener Institute for Polar and Marine Research (AWI), the GKSS Research Centre, the German Marine Research Consortium (KDM), the Leibniz Institute for Marine Sciences (IFM-GEOMAR), the United Nations University (UNU), the Federal Institute for Geosciences and Natural Resources (BGR), the German Agency for Technical Cooperation (GTZ), as well as from Indonesian and other international partners. Funding is provided by the German Federal Ministry for Education and Research (BMBF), Grant 03TSU01.

Edited by: J. Lauterjung

Reviewed by: S. Hettiarachchi and another anonymous referee 


\section{References}

Annaka, T., Satake, K., Sakakiyama, T., Yanagisawa, K., and Shuto, N.: Logic-tree approach for probabilistic tsunami hazard analysis and its applications to the Japanese coasts, Pure Appl, Geophys,, 164, 577-592, 2007.

Babeyko, A. Y., Hoechner, A., and Sobolev, S. V.: Source modeling and inversion with near real-time GPS: a GITEWS perspective for Indonesia, Nat. Hazards Earth Syst. Sci., 10, 1617-1627, doi:10.5194/nhess-10-1617-2010, 2010.

Basher, R.: Global early warning systems for natural hazards: systematic and people-centred, Philos. T. Roy. Soc. A, 364, 2167-2182, doi:10.1098/rsta.2006.1819, 2006.

Behrens, J., Androsov, A., Babeyko, A. Y., Harig, S., Klaschka, F., and Mentrup, L.: A new multi-sensor approach to simulation assisted tsunami early warning, Nat. Hazards Earth Syst. Sci., 10, 1085-1100, doi:10.5194/nhess-10-1085-2010, 2010.

Birkmann, J.: Indicators and criteria for measuring vulnerability: Theoretical bases and requirements, in: Measuring Vulnerability to Natural Hazards: Towards Disaster Resilient Societies, edited by: Birkmann, J., United Nations University Press, Tokyo, 9-54, 2006.

Borrero, J. C., Sieh, K., Chlieh, M., and Synolakis, C. E.: Tsunami inundation modeling for western Sumatra, P. Natl. Acad. Sci. USA, 103, 19673-19677, doi:10.1073/pnas.0604069103, 2006.

Burbidge, D., Cummins, P. R., Mleczko, R., and Thio, H. K.: A probabilistic tsunami hazard assessment for Western Australia, Pure Appl. Geophys., 165, 2059-2088, 2008.

Cardona, O. D.: Indicators of Disaster Risk and Risk Management - Program for Latin America and the Caribbean, Inter-American Development Bank Sustainable Development Department, Washington, DC, USA, 53 pp., 2005.

Chlieh, M., Avouac, J. P., Sieh, K., Natawidjaja, D. H., and Galetzka, J.: Heterogeneous coupling of the Sumatran megathrust constrained by geodetic and paleogeodetic measurements, J. Geophys. Res., 113, 1-31, 2008.

Cutter, S. and Flinch, C.: Temporal and spatial changes in social vulnerability to natural hazards, P. Natl. Acad. Sci. USA, 105(7), 2301-2306, 2008.

Dilley, M., Chen, R. S., Deichmann, U., Lerner-Lam, A., and Arnold, M.: Natural Disaster Hotspots. A Global Risk Analysis, The World Bank, Hazard Management Unit, Washington, DC, USA, 2005.

Federici, B. and Cosso, T.: Tsunami inundation maps and damage sceneries through the GIS GRASS, Proc. FOSS4G2006, 11-15 September, Lausanne, Switzerland, 172-181, 2006

Gayer, G., Leschka, S., Nöhren, I., Larsen, O., and Günther, H.: Tsunami inundation modelling based on detailed roughness maps of densely populated areas, Nat. Hazards Earth Syst. Sci., 10, 1679-1687, doi:10.5194/nhess-10-1679-2010, 2010.

Gebert, N. and Birkmann, J.: Socio-economic vulnerability assessment, Internal GITEWS Report, 99 pp., 2010.

Geist, E. L. and Parsons, T.: Probabilistic Analysis of Tsunami Hazards, Nat. Hazards, 37, 277-314, 2006.

González, F. I., Geist, E. L., Jaffe, B., Kânoğlu, U., Mofjeld, H., Synolakis, C. E., Titov, V. V., Arcas, D., Bellomo, D., Carlton, D., Horning, T., Johnson, J., Newman, J., Parsons, T., Peters, R., Peterson, C., Priest, G., Venturato, A., Weber, J., Wong, F., and Yalciner, A.: Probabilistic tsunami hazard assessment at Seaside, Oregon, for near- and far-field seismic sources, J. Geophys. Res.,
114, C11023, doi:10.1029/2008JC005132, 2009.

GTZ and DLR: Tsunami Hazard Maps for Bali, Technical Documentation, Denpasar, 2009.

Gutenberg, B. and Richter, C. F.: Seismicity of the Earth and Associated Phenomena, 2nd edn., Princeton University Press, 17-19, 1954.

Hanka, W., Saul, J.,Weber, B., Becker, J., Harjadi, P., Fauzi, F., and GITEWS Seismology Group: Real-time earthquake monitoring for tsunami warning in the Indian Ocean and beyond, Nat. Hazards Earth Syst. Sci., in press, 2010.

Khomarudin, M. R., Strunz, G., Ludwig, R., Zosseder, K., Post, J., Kongko, W., and Pranowo, W. S.: Hazard Analysis and Estimation of People Exposure as contribution to Tsunami Risk Assessment in the West Coast of Sumatra, the South Coast of Java and Bali, Z. Geomorphol., 54, Suppl. 3, 337-356, 2010.

Latief, H., Puspito, N. T., and Imamura, F.: Tsunami Catalog and Zones in Indonesia, Journal of Natural Disaster Science, 22(1), 25-43, 2000.

Lauterjung, J., Mnch, U., and Rudloff, A.: The challenge of installing a tsunami early warning system in the vicinity of the Sunda Arc, Indonesia, Nat. Hazards Earth Syst. Sci., 10, 641646, doi:10.5194/nhess-10-641-2010, 2010.

McCloskey, J., Antonioli, A., Piatanesi, A., Sieh, K., Steacy, S., Nalbant, S., Cocco, M., Giunchi, C., Huang, J. D., and Dunlop, P.: Tsunami Threat in the Indian Ocean from a Future Megathrust Earthquake West of Sumatra, Earth Planet. Sc. Lett., 265, 61-81, 2008.

Post, J., Mück, M., Zosseder, K., Steinmetz, T., Riedlinger, T., Strunz, G., Mehl, H., Dech, S., Birkmann, J., Gebert, N., Anwar, H. Z., and Harjono, H.: Tsunami risk assessment for local communities in Indonesia to provide information for early warning and disaster management, International Conference on Tsunami Warning (ICTW), Bali, Indonesia, 7 pp., 12-14 November 2008.

Post, J., Wegscheider, S., Mück, M., Zosseder, K., Kiefl, R., Steinmetz, T., and Strunz, G.: Assessment of human immediate response capability related to tsunami threats in Indonesia at a sub-national scale, Nat. Hazards Earth Syst. Sci., 9, 1075-1086, doi:10.5194/nhess-9-1075-2009, 2009.

Power, W., Downes, G., and Stirling, M.: Estimation of tsunami hazard in New Zealand due to South American earthquakes, Pure Appl. Geophys., 164, 547-564, 2007.

Raape, U., Fauzi, Riedlinger, T., Tessmann, S., Wnuk, M., Hunold, M., Kukofka, T., Strobl, C., Mikusch, E., and Dech, S.: A newly developed decision support system for improved tsunami early warning in Indonesia, Proc. International Conference on Tsunami Warning (ICTW), Bali, Indonesia, 8 pp., 12-14 November 2008

Rudloff, A., Lauterjung, J., Münch, U., and Tinti, S.: Preface "The GITEWS Project (German-Indonesian Tsunami Early Warning System)", Nat. Hazards Earth Syst. Sci., 9, 1381-1382, doi:10.5194/nhess-9-1381-2009, 2009.

Schneiderbauer, S.: Risk and Vulnerability to Natural Disasters From Broad View to Focused Perspective, Dissertation, Freie Universität Berlin, Germany, 2007.

Sieh, K., Natawidjaja, D. H., Meltzner, A. J., Shen, C. C., Cheng, H., Li, K. S., Suwargadi, B. W., Galetzka, J., Phillibosian, B., and Edwards, R. L.: Earthquake Supercycle Inferred from SeaLevel Change Recorded in the Coral of West Sumatra, Science, 
322, 1674-1677, 2008.

Steinmetz, T., Raape, U., Teßmann, S., Strobl, C., Friedemann, M., Kukofka, T., Riedlinger, T., Mikusch, E., and Dech, S.: Tsunami early warning and decision support, Nat. Hazards Earth Syst. Sci., 10, 1839-1850, doi:10.5194/nhess-10-1839-2010, 2010.

Sumaryono, S., Strunz, G., Ludwig, R., Post, J., and Zosseder, K.: Measuring urban vulnerability to tsunami hazards using integrative remote sensing and GIS approaches, International Conference on Tsunami Warning (ICTW), Bali, Indonesia, 9 pp., 2008

Turner, B. L., Kasperson, R. E., Matson, P. A., McCarthy, J. J., Corell, R. W., Christensen, L., Eckley, N., Kasperson, J. X., Luers, A., and Martello, M. L.: A framework for vulnerability analysis in sustainability science, Proceedings of the National Academy of Sciences, 100, 8074-8079, 2003.

UNESCO-IOC: Hazard Awareness and Risk Mitigation in Integrated Coastal Management (ICAM), UNESCO, Paris, IOC Manuals and Guides, No 50, 2009a.

UNESCO-IOC: Tsunami Risk Assessment and Mitigation for the Indian Ocean: knowing your tsunami risk - and what to do about it, UNESCO, Paris, IOC Manuals and Guides, No 52, 2009b.
United Nations Development Programme (UNDP): Reducing Disaster Risk: A Challenge for Development. A Global Report, New York: UNDP, Bureau for Crisis Prevention and Recovery (BRCP), 2004.

UN/ISDR: Global survey of early warning systems, United Nations International Strategy for Disaster Reduction, Geneva, 56 pp., 2006.

Wegscheider, S., Post, J., Mück, M., Zosseder, K., Riedlinger, T., Gebert, N., Anwar, H., and Muhari, A.: Generating tsunami risk knowledge at community level as a base for planning and implementation of risk reduction strategies, EGU General Assembly, Vienna, 2010, Geophysical Research Abstracts, Vol. 12, EGU2010-8450, 2010.

Wisner, B., Blaikie, P., Cannon, T., and Davis, I.: At risk: natural hazards, people's vulnerability and disasters, 2nd edn., Routledge, London, 2004.

Zosseder, K., Post, J., Steinmetz, T., Wegscheider, S., and Strunz, G.: Using Multi-Scenario Tsunami Modelling Results combined with Probabilistic Analyses to provide Hazard Information for the South-West Coast of Indonesia, EGU General Assembly, Vienna, 2009, Geophysical Research Abstracts, Vol. 11, EGU2009-12635, 2009. 